\title{
Intelligent Information Management with Digitization Workflow
}

\author{
Surachet Channgam, Prachyanun Nilsook, and Panita Wannapiroon
}

\begin{abstract}
This research aims to study the intelligent information management with Digitization workflow, to synthesize the intelligent information management with Digitization workflow and evaluate the intelligent information management with Digitization workflow. By conducting research from related works and comparing and analyzing the intelligent information management model with Digitization workflow, the pattern model which has been synthesized was found by the researcher. The intelligent information management model with Digitization workflow is consists of 6 elements, 1) Create 2) Capture 3) Management 4) Deliver 5) Preserve and 6) Analytics. Each elements also divided into sub-module as follows; Create divided into 3 sub-modules which are creation and writing content sub-module, sync file and share sub-module, and social and collaboration sub-module; Capture divided into 2 sub-modules which are multi-channel capture sub-module and data recognition, standards and extract sub-module; Management divided into 4 sub-module which are metadata management sub-module, document version control sub-module, data-collection management and electronic portfolio sub-module, and digital asset management sub-module; Deliver divided into 4 sub-modules which are enterprise search sub-module, transformation technology sub-module, security technology sub-module, and content distribution sub-module; Preserve divided into 3 sub-modules which are records management and distribution sub-module, compliance-government and industry sub-module, and legal and electronic transaction sub-module; and finally Analytic divided into 3 sub-module which are semantics and text analytical sub-modules, system auditing and monitoring sub-module, and content and process analytics sub-module. To evaluation results of the design of intelligent information management with Digitization workflow, the result found that the appropriate of workflow design is at very high levels
\end{abstract}

Index Terms-Intelligent information management, digitization workflow.

\section{INTRODUCTION}

Technology has developed rapidly and came to be important role both in daily life and work for recently years. With technology that is changing rapidly and constantly changing, all agencies, both government and private sectors have more need to use technology in the operation of the organization to reform accurate, fast and the most modern to

Manuscript received June 18, 2019; revised October 11, 2019

$\mathrm{S}$. Channgam is with the Division of Information and Communication Technology for Education, Faculty of Industrial Education, King Mongkut's University of Technology North Bangkok (KMUTNB), Thailand (e-mail: chet037@gmail.com).

P. Nilsook and P. Wannapiroon are with the Division of Information and Communication Technology for Education, Faculty of Technical Education, King Mongkut's University of Technology, North Bangkok (KMUTNB), Thailand (e-mail: prachyanunn@kmutnb.ac.th, panitaw@kmutnb.ac.th). be competitive advantage. In addition to technology, one of the important factors and coupled with the technology that makes the organization survive and compete with competitors is the availability of up-to-date information to immediately plan and support the decisions of high-level managers. Therefore, every organization need technology or tools to support the decision that is the right decision.

Rapidly technology changes do not only affect people's lifestyle by increasing consumption options and facilitating various aspects, but also affecting the business model, work procedures, production and service through both locally and internationally economic environment. The competition is more intense and strongly in all sectors, whether public, private sector and industrial sectors. Also education sector, it is necessary to accelerate the development and increase their competitiveness with the rapid technology.

At this present, university is a highly competitive educational organization cause of the large number new courses have been opened by universities as an alternative to those interested in studying according to their aptitudes, abilities and preferences. At the same time, the number of students enrolled at the university has decreased and many universities transform into an informal university which budget has less receive from government. Therefore, every university has a high level of competition in every area. Thus, university administrators need to use Information Technology and Communication (ICT) as a tool or participate in management and making decisions that are fast and accurate. Additional, the educational institution has a lot of information generated from activities in teaching, research and administration. This information should be easily transmitted to various agencies so it is necessary to organize and manage the information carefully. In order to avoid overlapping of information that occurs in existing internal systems [1].

Intelligent Information Management is a new world of information and content management. But with a set of instructions that facilitates work more than the past. While data and content management, the problem is categorized and focused primarily on service issues. That needs to be improved and to be suitable for the current technology performance that is entering the era of intelligent data and content management.

From the above circumstances, it can be seen that the current situation of educational institutions has reduced some types of expenses and has developed a system for collect new forms of data to be supported by converting data to digital format. At the same time, the starting with the improvement of digital work processes to discover new needs in the organization, the creation of new Digitization workflow processes to be as comprehensive and as simple as possible. 
Because it is planned to cooperate with other departments. The other goal of the updates is to standardize all processes, including image formats used to store and publish in digital documents which received special attention in setting standards for naming digital documents related to future workflow systems [2].

Workflow is the name to call various activities that proceeds in a continuous sequence from the beginning to the end of the activity in that work stream, which begins when being stimulated by input or news. When the first activity is completed, it will deliver the burden to other activities continuously until the end of the activity in that workflow. Or until the last activity that is unable to make other activities can work anymore. When considered in this respect, it can say that the word "workflow" will continue to focus on the movement of data and information from one activity to another until the end of the work that must be done with that information or activity.

The documented workflows is increase flexibility in various processes and related tasks to digital data transform projects to facilitate consistency and results are reliable. Especially, when dealing with large objects that are digitized documentation about workflows is important for tracking content in each step and identifying errors or problems. Workflow Management is a work procedure management system with a step-by-step. By set the work procedure, follow up work and including the approval of various documents are related to each step. The efficient operation, including being able to monitor work procedures in the status of operation and audit the delay in the actions that occur can be used to improve. And this is an indicator of the risk that will occur with the achievement of the work from the beginning of the process through the end of the process.

To make the use of the system convenient, the system should be flexible and develop according to the situation of technology. Therefore, it has developed a system that can be used in conjunction with portable devices more easily, by applying the principle of the face recognition system to identify and authentication in accessing information. The human face indicates a lot of information about the identity and emotional state of the person. Face recognition is an interesting problem and challenging and affecting the use in many areas, including facial expressions, feature extraction and classification. The facial expression is an approach to create a face model and define algorithms for continuous detection and recognition with useful and unique features of this face image. There are separated in the process of extracting features in the classification of the face image, it is compared with the face image that is stored in the database [3].

Beside the present technology being newly developed and widely used, especially in high speed internet communication has become more important in everyday life of mankind. At the same time, there is not only need to rely on a PC (Personal Computer) because today's portable communication devices can support interchangeability makes it easier to communicate with each other or search for information via the internet. The website developers have designed the website to be flexible and support the use of intelligent devices or called Smart Device effectively.

Smart Device is an electronic device can connect to other devices or wireless networks through different protocols and can communicate or respond to many types. This intelligent device is the combination name of the smartphone (Smart Phone) and the tablet, which is easily separated by if the screen is smaller than 5 inches, it is called a smartphone. If the screen is larger than 5 inches, it is called a tablet, A smart device is a portable device which many applications can support internet usage via $3 \mathrm{G}$, Wi-Fi and social networks or popular chat applications such as LINE, YouTube, Facebook Messenger, Twitter, etc. Users can customize smartphones to the needs more than ordinary mobile phones. The manufacturers of new smartphones are produce smartphones with touch screen and settle a high resolution camera. The design is stylish and beautiful. There are interesting applications and functions.

A university that is a tertiary education institution that prepares people for a career that requires knowledge and skills. Through that knowledge, students will study in the classroom according to the content specified in the course [4]. The university's graduation criteria have been set for teaching and learning in higher education institutions generally consists of 4 types of activities: theoretical classes in the classroom, practical study in the laboratory, basic training in schools and short period professional training. The professional experience training is a part of the educational management process at the tertiary level which aims to enhance students to have direct experience in working as learning situations and real situations of work. As well as being able to apply the knowledge obtained in theory and practice to trial in order to emphasize the true clarity in the knowledge gained which will be useful for students in preparing every aspect of behavior, whether in the personality, intelligence, good attitude, right and proper in order to go out to live and work professionally effectively, ultimately socializing.

\section{LITERATURE REVIEW}

\section{A. Intelligence Information Management}

Intelligence Information Management is a complex information management which has to manage strategic information, methods and tools to create, automatic capture, management, delivery, security and content analysis and documents related to the organization's work processes. Which the organization is considered a modern perspective and integrated information management. Understand and expectation of customers both inside and outside Making a basic digital structure Improvement of modern information infrastructure Compliance with rules and supervision by automated systems Utilization of analytical and mechanical learning

\section{B. Digitization Workflow Management}

Digitization Workflow Management is an application of workflow management system [5] has implemented the WFMS model that has been adopted, with a consistent and flexible program format that provides a number of modular workflow management services and [6] explored the needs of enterprise data management and explained the design of document management systems. To allow users in the 
organization to have a simple and efficient system to access information, manage and share information, basic document management, enhances the efficiency of personal document management and increases the efficiency of collaboration among users.

\section{Face Recognition}

Face Recognition is the access security to the system by face personal identification [7]. Face recognition in an environment without limitations which compares the face recognition system and the advanced face recognition method for environments with no definition, such as gestures, illumination, change in expression [8] present examine algorithm on mobile phone using color segmentation and template matching for face detection. There is a limitation for face detection algorithms. If the background color of the image is similar to the skin color, the color segmentation algorithm will not be able to distinguish. In the template matching template, our results depend on the standard template that selects the illumination state and has proposed an intelligent prototype to control access to the system by means of a person's face identification method. Which uses biometric technology to check the system access by proving the person's face by comparing individual face features Individual proofs using still images. And draw the characteristics of the person's face by using Feature-based Approach to find the left eye position, right eye position and mouth. Additional, use Circular Hough Transform (CHT) to search for areas of the eye on the face and using Robert Edge Detection to search for areas of the mouth on the face. In addition, the algorithm used to find the similarities of face vectors used to compare individual face templates for identification verification.

\section{Digital Workforces}

Digital Workforces in a world that became to enter the era of digital economy and society. Digital technology is not just a part of a tool that support work as before. But it will truly integrate into the lives of people in the modern era and changed the structure of economic activities, production processes, trade, services and other social processes. Including the interaction between individuals has completely changed. Organizations, including government and private sectors have to adjust and change the organization by adopting modern digital technology into the organization. To improve the performance of the organization better, which is considered a driving force economic and social development of the country as well. Preparation for Thailand 4.0 has a guideline to develop digital technology skills of government officials and government personnel [9]. To have knowledge and use technology as to be transformed into a digital government. By developing skills, understanding and using digital technology or digital literacy, such as skills in bringing digital tools, equipment and technology that are currently available, including computers, phones, tablets, computer programs and online media, to be used for maximum benefit in communication of operations and collaborative or used to develop work processes or the system in the organization to be modern and efficient. The development of skills covers 4 dimensions, including 1) use 2) understanding 3) creation and 4) digital technology access effectively. One of the important resources for successful design and strategy implementation to change to a digital organization is to have the leaders of the organization and the staff that specializes in technology. But a variety of digital innovations, new technologies, also contribute to the foundation for organizational change to digital as well [10]. Therefore, in a rapidly changing development, there have skills, understanding and using 9 digital technologies as follow:
1. Computer skills
2. Internet skills
3. Cyber security awareness
4. Presentation programs
5. Word processing
6. Spreadsheets
7. Online collaboration
8. Graphics editors
9. Cyber security practices

\section{E. Professional Experience}

Professional Experience requires the preparation in the field of professional experience which consists of 3 properties which are attitude, characteristics and knowledge and skill qualifications [11]. The internship for students is a real learning experience in the workplace for students to benefit from knowledge and understanding from work. According to the student's aptitude [12], from the results of the study, it was found that the guidelines for the use of information and communication technology to be used as a support system for professional experience management has collection documentation system, workspace management system, cooperation management system and evaluation of professional experience system.

\section{MethodOlOGY}

TABLE I: SyNTHESIS OF INTELLIGENT DATA MANAGEMENT WITH DIGITIZATION WORKFLOWS

\begin{tabular}{|c|c|c|c|c|c|c|c|c|c|c|c|}
\hline & & IZATI & $\mathrm{DN}$ & $O R$ & $\mathrm{GI}$ & & & & & & \\
\hline $\begin{array}{l}\text { Module of the } \\
\text { Intelligent } \\
\text { Information } \\
\text { Management }\end{array}$ & 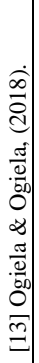 & 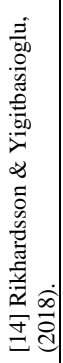 & 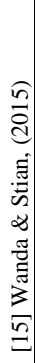 & 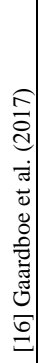 & 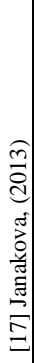 & 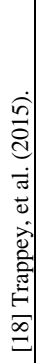 & 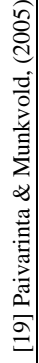 & 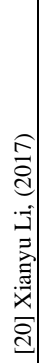 & 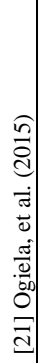 & 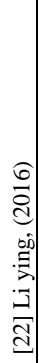 & 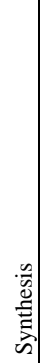 \\
\hline 1. Create & $\checkmark$ & $\checkmark$ & $\checkmark$ & & $\checkmark$ & $\checkmark$ & $\checkmark$ & $\checkmark$ & $\checkmark$ & & $\checkmark$ \\
\hline 2. Capture & $\checkmark$ & $\checkmark$ & $\checkmark$ & $\checkmark$ & $\checkmark$ & & $\checkmark$ & $\checkmark$ & $\checkmark$ & $\checkmark$ & \\
\hline 3. Manage & $\checkmark$ & & & $\checkmark$ & $\checkmark$ & $\checkmark$ & & $\checkmark$ & $\checkmark$ & $\checkmark$ & $\checkmark$ \\
\hline 4. Automate & $\checkmark$ & & $\checkmark$ & & & $\checkmark$ & $\checkmark$ & & & $\checkmark$ & \\
\hline 5. Collaboration & & & $\checkmark$ & & $\checkmark$ & & & & $\checkmark$ & & $\checkmark$ \\
\hline 6. Deliver & $\checkmark$ & $\checkmark$ & & $\checkmark$ & $\checkmark$ & $\checkmark$ & $\checkmark$ & $\checkmark$ & & $\checkmark$ & $\checkmark$ \\
\hline 7. Preserve & & $\checkmark$ & $\checkmark$ & & $\checkmark$ & $\checkmark$ & $\checkmark$ & $\checkmark$ & $\checkmark$ & $\checkmark$ & $\checkmark$ \\
\hline 8. Backup & $\checkmark$ & & & & $\checkmark$ & $\checkmark$ & & & $\checkmark$ & $\checkmark$ & \\
\hline 9. Eliminate & $\checkmark$ & & & $\checkmark$ & & & & $\checkmark$ & & & $\checkmark$ \\
\hline 10. Analytics & & $\checkmark$ & $\checkmark$ & $\checkmark$ & $\checkmark$ & & $\checkmark$ & $\checkmark$ & $\checkmark$ & & $\checkmark$ \\
\hline
\end{tabular}

The research methodology is divided into 3 phases according to the research objectives as follows:

Phase 1: Analysis of the related theory and research documents to synthesize the conceptual framework of intelligent information management with digitization workflows the researcher has studied some documents and 
then analyzed the content and synthesized the relevant research work in the amount of 10 items.

Phase 2. Analyze content and create synthesis tables about intelligent information management with Digitization workflows. The result found that intelligent information management with a Digitization workflow consists of 6 components: 1) Create, to import digital documents into the system 2) capture, is responsible for data creation 3) document information management 4) Deliver, is the delivery of existing information response to user data requestor. 5) Storage (Preserve) Prevent data loss and 6) Analysis (Details) will be shown in Table I.

Phase 3. The appropriate assessment of intelligent information management with Digitization workflow is a process that is used to assess suitability by using experts who are competent and experienced in intelligent information management with Digitization workflow, totally 5 people.

\section{RESULT}

Intelligence Information Management procedures from Ogiela \& Ogiela [13], Rikhardsson \& Yigitbasioglu [14], Wanda \& Stian [15], Gaardboe, Nyvang, \& Sandalgaard [16], Janakova [17], Trappey, Trappey, Ma, \& Chang [18], Paivarinta \& Munkvold [19], Xianyu Li [20], Ogiela \& Ogiela [21], and Li Ying [22].

The synthesis results of related research in the field of intelligent information management with Digitization workflow from Table I found that the process of managing information with Digitization workflow consists of 6 main components, 19 sub-elements, as follows

Component 1 Create: Import digital documents into system

1.1 Creation and writing content

1.2 Sync files and share

1.3 Social and Collaboration

Component 2 Capture: Responsible for creating data by transform paper documents into digital document formats and is collect in an electronic document format which is easy to maintain and manage. There is 2 sub-modules as follow

\subsection{Multi-channel capture}

2.2 Data recognition, standards and extraction. Recognition technology that accepted paper data to be converse into electronic data without manual input.

Component 3 Document Management. There is 4 sub-modules as follow

3.1 Metadata management

3.2 Document Version

3.3 Data-collection management and electronic portfolio

3.4 Digital asset

Component 4 deliver. Delivery of existing data to the user who request data according to the right

4.1 Enterprise Search. It is used to retrieve documents that have already been stored by cooperate with the management, store and preserve document. After retrieve document, it converts the document data to the desired format

4.2 Transformation Technologies. Technology that transform documentation into desired format such as Personalization, XML, PDF, XPS, Compression and Syndication. Then, document may be encrypted for security.

4.3 Security Technologies. It is an encrypted technology for security using Public Key/ Digital Rights Management /Watermark /Digital Signature etc.

4.4 Content Distribution. It is the distribution and delivery of the desired document through the appropriate format conversion including security encryption to various sources. For example, paper, Internet, e-Mail, Mobile Devices, Digital TV and other Data Media etc.

Component 5 Preserve. Is responsible for store all documents as long as possible and also make a backup plan for document management and work processes of the system.

5.1 Records management and distribution

5.2 Compliance-government \& industry

5.3 legal and electronic transactions

Component 6 Analytics. Data that has been preserved can be analyzed for planning, tracking the movement of data

6.1 Semantics and text analytics

6.2 System auditing and monitoring

6.3 Content and process analytics

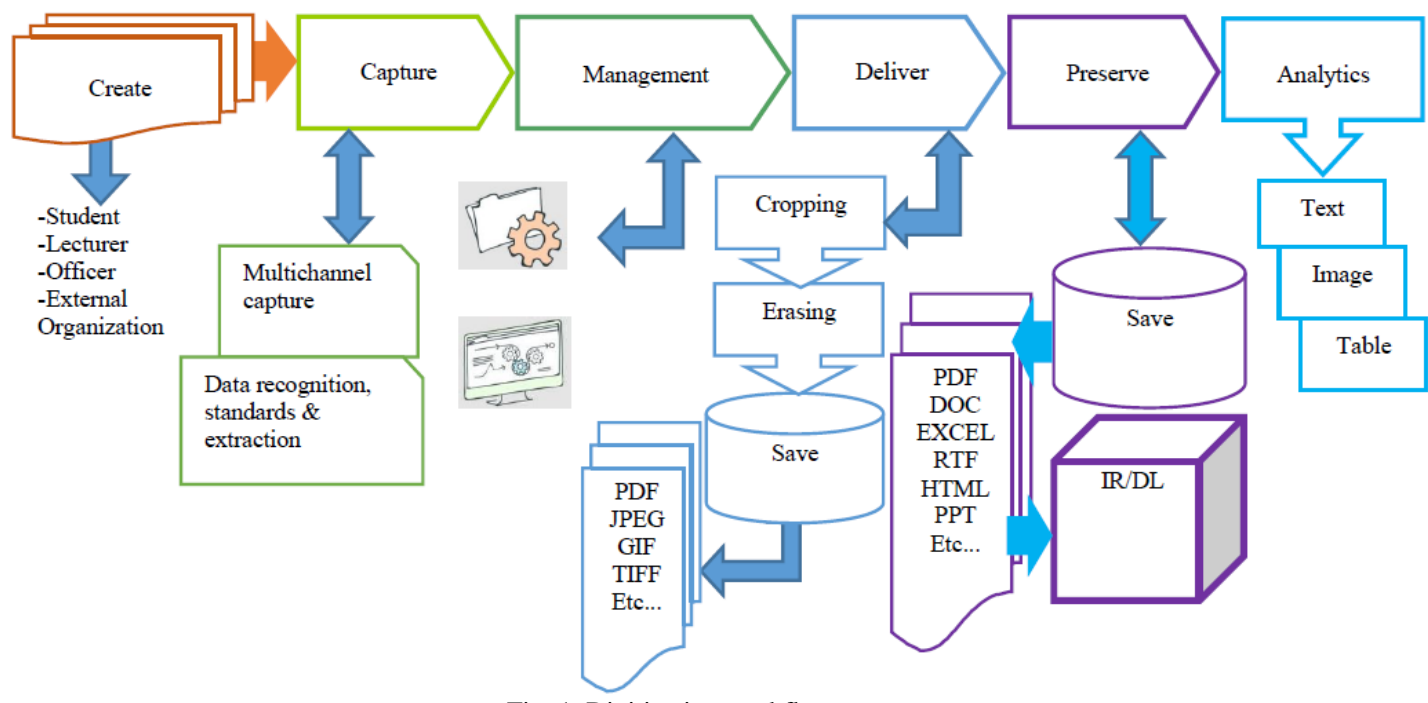

Fig. 1. Digitization workflow process.

From Fig. 2. The architecture design for intelligent information management with digitization workflow consists of 3 components as follow
1. Front office service - is a cloud service. Software service model (SaaS) through the user interface through the application (application user interface), which has 
sub-elements including

1.1) Monitoring - used as a channel for monitoring and providing data services. It has links, data transfer. Moreover, it checked the reliability and security of data. The organization use the network management system so it is possible to solve problems quickly.

1.2) Laptop - is a device that administrators and staff use to enter data into the system through applications. For the user, use the services through the user interface on the browser.

1.3) Smartphone - is a device that users of the system use to access information and services through the user interface on the browser or application. Which is more convenient and faster than computers because it can be carried to use anywhere, anytime through the internet.

1.4) Browser - is a software that accesses data and services through the user interface known as web applications. Which can be used on computers and smartphones. For smartphones, it will be used directly through the application.

1.5) Social Network - is the media used for public relations, exchange of ideas and ask for help from the moderator for communication between students, personnel in educational institutions, establishment and the general public quickly and efficiently.

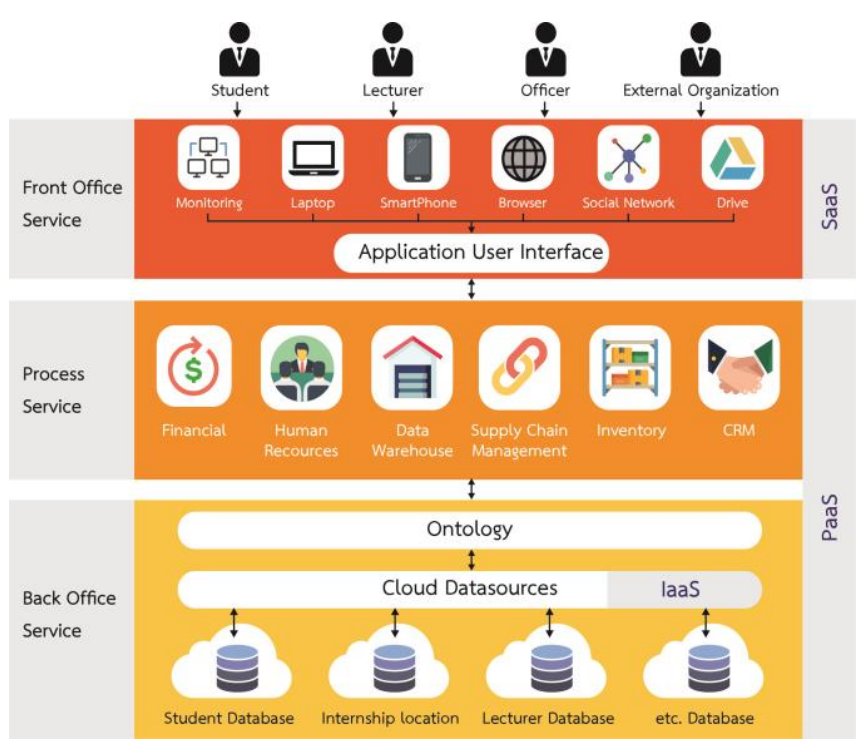

Fig. 2. System architecture.

2. Service Process is a service for organizations on cloud technology, platform service (PaaS). Administrators will provide services in various platforms as follows.

2.1) Financial - Support financial planning in accordance with various project tasks both revenue and expenditure of the training center.

2.2) Human resources - Support, coordination and support communication between organizations and personnel of the training center. Facilitate information that administrators and educational service providers need to create and edit student information.

2.3) Data Warehouse - is used to collect all data in the training center into the data database

2.4) Supply Chain Management: SCM - is the planning and management of students to have the appropriate amount for the needs of the establishment. Including the arrangement of materials for various activities to have the amount appropriate for the number and needs of students.
2.5) Inventory - is the control of various equipment to students. From the purchasing process, inspection of materials, equipment, borrowing and distribution. In order to know the amount of materials and equipment remaining as actual.

2.6) Customer relationship management: CRM - is a strategy that creates value between educational institute and students. For students, to receive good service, efficient and effective that causing a good relationship with each other.

3. Back office service - is a service for overseer and those who have imported data into a database on a cloud, the platform-based technology (PaaS) service consists of the following parts:

3.1) Ontology - is the part of extracting data from the data center to collect data according to the type of usage that is related in the training center.

3.2) Cloud Data Sources - is a collection of related data on cloud technology, hardware infrastructure and storage space. By sorting from the topology according to the type of usage which the organization of each organization has separated the data into various categories, which are student information, information of establishments, information of teachers, etc. The number of databases on the cloud depends on the structure of each organization.

\section{DISCUSSION}

The study of intelligent information management with Digitization workflow. The researchers conducted a study comparing different models and in Table I were synthesized scientific research papers and the Corinthians. Involves intelligent information management processes with Digitization workflow. Therefore, would like to discuss the results as follows

1. Analysis of documents and related research results together with the synthesis of intelligent information management processes with Digitization workflows. The researchers have the format as shown in Figure 3, which the researcher's style consists of 6 components, including 1) Create 2) Capture 3) Management 4) Deliver 5) Preserve and 6) Analytics. The researchers selected a total of 6 components. Which is consistent with research [13], [14].

2. The result of the synthesis of intelligent information management with Digitization workflow. The researchers found that the intelligent information management process with Digitization workflow consists of 6 modules, 19 sub-modules, including module 1 Create has 3 sub-modules, including content creation and writing sub-modules, Sync and file sharing module and Social and collaboration sub-module. Which corresponds to the research work [15], resulting in fast document creation work. Module 2 Capture has 2 sub-modules, including multi-channel capture sub-modules and data recognition sub-module and standard for data extraction Which corresponds to the research [21], allowing the system to capture document data in a systematic and convenient way to search. Module 3 Management There are 4 sub-modules, including the metadata management module, Document version control module, Information management module for electronic records and portfolios and digital asset management module. Which corresponds to the research work [15], [23], resulting in the ability to manage 
the document information correctly and efficiently. Module 4 Deliver has 4 sub-modules, consisting of enterprise information search module, Data conversion technology module, Security technology module and Content distribution module. Which corresponds to the research work, making it safer to deliver documents. Module 5 Preserve has 3 sub-modules, consisting of recording and distribution management modules, Regulatory compliance module government and industry and Electronic laws and transaction module [24], [25]. Which corresponds to the research, helps to keep the document data effective and in accordance with the law. And finally, module 6 Analytics has 3 sub-modules consisting of text semantic analysis module, Tracking and monitoring systems module and Process and content analysis. Which is consistent with the research by helping to increase the efficiency of analyzing the potential for job applications and future work guidelines.

3. Evaluation results from 5 experts has evaluated the design of intelligent information management Digitization workflow. The statistics used in this research are mean and standard deviation. The research showed that very high levels with average point at 4.70 , S.D. is 0.45 . The principle in this research for intelligent information management with Digitization Workflow. The research showed that very high levels with average point at 4.50, S.D. is 0.65. System framework for an intelligent information management with Digitization Workflow. The research showed that very high levels with average point at 4.60, S.D. is 0.55 . Relevant persons for intelligent information management with Digitization Workflow. The research showed that very high levels with average point at 4.50, S.D. is 0.55. Modules of Intelligent information management with Digitization Workflow. The research showed that very high levels with average point at 4.50, S.D. is 0.55. Cloud Computing. The research showed that very high levels with average point at 4.50, S.D. is 0.65 . Intelligent information management with Digitization Workflow can apply to daily life. The research showed that very high levels with average point at 4.70, S.D. is 0.53 . Which corresponds to the research work [26], [27].

\section{CONCLUSION}

In this paper, we have studied the intelligent information management with Digitization workflow, to synthesizing documents from various research related to intelligent information management with Digitization workflow and finally evaluated intelligent information management with Digitization workflow. The results of the research can be summarized as follows:

1. The intelligent information model with Digitization workflow. Which consists of 6 components, 1) Create 2) Capture 3) Management 4) Deliver 5) Preserve and 6) Analytics

2. Each component also divided into sub-module as follows; 1) Create module there are 3 sub-modules consisting of content creation and writing modules, Sync and file sharing module and Social and collaboration modules. 2) Capture module there are 2 sub-modules, including multi-channel capture module and Data recognition and data extraction standard module. 3) Management module there are 4 sub- modules consisting of a metadata management module, Document version control module, Information management module for electronic records and portfolios and Digital asset management module. 4) Deliver module has 4 sub-modules, consisting of Enterprise information search module, Data conversion technology module, Security technology module and Content distribution module. 5) Preserve module there are 3 sub-modules consisting of Recording and distribution management module, Compliance-government and industry module and Legal and electronic transaction module. And finally 6) Analysis module has 3 sub-modules consisting of Semantics and text analytical modules, System auditing and monitoring sub-module and Content and process analytics module. All modules can help intelligent data management. Which is a complex data management and manage documents related to work processes in the organization.

3. To evaluation results of the design of intelligent information management with Digitization workflow, the result found that the appropriate of workflow design is at very high level with average point at 4.70, S.D. is 0.53 .

\section{ACKNOWLEDGMENT}

The researcher would like to thank you. Faculty of Management Science, Chandrakasem Rajabhat University, Division of Information and Communication Technology for Education, Faculty of Industrial Education, Vocational Technology Research Center, Innovation and Technology Management Research Center Bureau of Science and Technology Research, King Mongkut's University of Technology North Bangkok, which supports this research.

\section{REFERENCES}

[1] C. Maican and R. Lixandroiu, "A system architecture based on open source enterprise content management systems for supporting educational institutions," Int. J. Inf. Manage., vol. 36, no. 2, pp. 207-214, 2016.

[2] J. Mancini, "The next wave: Moving from ECM to intelligent information management," AIIM Eb. Intell. Inf. Manag., pp. 1-13, 2017.

[3] A. Rahim, N. Hossain, T. Wahid, and S. Azam, "Face recognition using Local Binary Patterns (LBP)," Glob. J. Comput. Sience Technol. Graph. Vis., vol. 13, no. 4, pp. 469-481, 2013.

[4] K. Sarnok, P. Wannapiroo, and P. Nilsook, "Digital learning ecosystem by using digital storytelling for teacher profession students," Int. J. Inf. Educ. Technol., vol. 9, no. 1, pp. 21-26, 2018.

[5] A. Al-Barakati, M. White, and Z. Patoli, "The application of workflow management to digital heritage resources," Int. J. Inf. Manage., vol. 34, no. 5 , pp. 660-671, 2014.

[6] C. H. Kao and S. T. Liu, "Development of a document management system for private cloud environment," Procedia - Soc. Behav. Sci., vol. 73, pp. $424-429,2013$.

[7] A. K. Agrawal and Y. N. Singh, "Evaluation of face recognition methods in unconstrained environments," Procedia Comput. Sci., vol. 48, no. C, pp. 644-651, 2015.

[8] G. Dave, X. Chao, and K. Sriadibhatla, "Face recognition in mobile phones," Dep. Electr. Eng. Stanford Univ. USA, no. February, 2010.

[9] S. Lissitsa, S. Chachashvili-Bolotin, and Y. Bokek-Cohen, "Digital skills and extrinsic rewards in late career," Technol. Soc., vol. 51, pp. 46-55, 2017.

[10] A. I. Canhoto, S. Quinton, P. Jackson, and S. Dibb, “The co-production of value in digital, university-industry R\&D collaborative projects," Ind. Mark. Manag., vol. 56, pp. 86-96, 2016.

[11] D. Sompong, S. Jinjo, S. Kukanok, and P. Phomasakha Na Sakolnakorn, "A development of internship management system by using information and communications technology," Sakon Nakhon Rajabhat Univ. J., vol. 6, no. 11, pp. 65-80, 2014.

[12] D. Ktoridou and E. Doukanari, "Task-based internships : Fostering ideal learning through focused experience," in Proc. 2017 IEEE Global Engineering Education Conference, 2017, pp. 1717-1722.

[13] M. R. Ogiela and L. Ogiela, "Cognitive cryptography techniques for intelligent information management," Int. J. Inf. Manage., vol. 40, no. January, pp. 21-27, 2018. 
[14] P. Rikhardsson and O. Yigitbasioglu, "Business intelligence \& analytics in management accounting research: Status and future focus," Int. J. Account. Inf. Syst., vol. 29, pp. 37-58, 2018.

[15] P. Wanda and S. Stian, "The secret of my success: An exploratory study of business intelligence management in the norwegian industry," Procedia Comput. Sci., vol. 64, no. 1877, pp. 240-247, 2015.

[16] R. Gaardboe, T. Nyvang, and N. Sandalgaard, "Business intelligence success applied to healthcare information systems," Procedia Comput. Sci., vol. 121, pp. 483-490, 2017.

[17] M. Janakova, Information and Data Management with Links on Business and Swarm Intelligence.

[18] A. J. C. Trappey, C. V Trappey, L. Ma, and J. C. M. Chang, "Computers \& industrial engineering intelligent engineering asset management system for power transformer maintenance decision supports under various operating conditions," Comput. Ind. Eng., vol. 84, pp. 3-11, 2015.

[19] T. Päivärinta and B. E. Munkvold, "Enterprise content management : An integrated perspective on information management," in Proc. 38th Annual Hawaii International Conference on System Sciences, 2005, pp. $1-10$.

[20] X. Li, "The intelligent technologies of electronic information system," $J$. Phys. Conf. Ser., vol. 887, no. 1, 2017.

[21] L. Ogiela and U. Ogiela, "Information security in intelligent data management processes," in Proc. 2015 10th Int. Conf. Broadband Wirel. Comput. Commun. Appl, 2015., pp. 169-172.

[22] Y. Li, "Design and implementation of the management information system for Chain business corporation," in Proc. 2016 8th Int. Conf. Meas. Technol. Mechatronics Autom., 2016, pp. 195-198.

[23] A. Di Iorio and M. Schaerf, "The organization information integration in the management of a digital library system," IEEE/ACM Jt. Conf. Digit. Libr., pp. 461-462, 2014.

[24] A. Samir, B. Elsayed, N. Adly, M. Nagi, and E. Shatby. (2016). Digitizing egyptian national documents archive: Challenges and solutions. $\quad$ [Online]. Available: http://wiredspace.wits.ac.za/bitstream/handle/10539/20509/Digitizing\% 20Egyptian\%20National\%20Documents\%20Archive_FINAL.pdf?sequ ence $=1 \&$ isAllowed $=\mathrm{y}$

[25] I. Pappel, I. Pappel, and M. Saarmann, "Digital records keeping to information governance in estonian local governments," in Proc. Int. Conf. Inf. Soc. (i-Society 2012) Digit., 2012, pp. 199-204.

[26] R. Laoha, P. Wannapiroon, and P. Nilsook, "The system architecture of digital activity portfolio via internet of things fordigital university,"
International Journal of Advanced and applied Sciences, vol. 6, no. 2, pp. 81-86, 2019

[27] A. Sanglub, P. Nilsook, and P. Wannapiroon, Imagineering on Augmented Reality and Digital Twin for Digital Competence, vol. 9, no. 3, 2019.

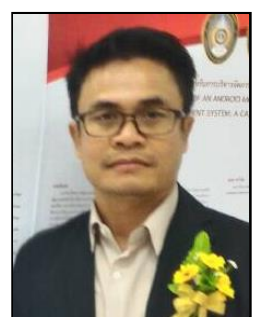

Surachet Channgam is a Ph.D candidate in Division of Information and Communication Technology for Education, Faculty of Technical Education, King Mongkut's University of Technology North Bangkok (KMUTNB). He is a lecturer at the Department of Business Computer, Faculty of Management Science, Chandrakasem Rajabhat University, Thailand. His research interest include data mining, data analytics, and machine learning.

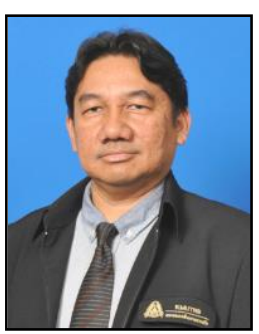

Prachyanun Nilsook is an associate professor at the Division of Information and Communication Technology for Education, Faculty of Technical Education, King Mongkut's University of Technology North Bangkok (KMUTNB), Thailand. He currently works in the field of ICT for education. He is a member of the professional society, the Association for Educational Technology of Thailand (AETT).

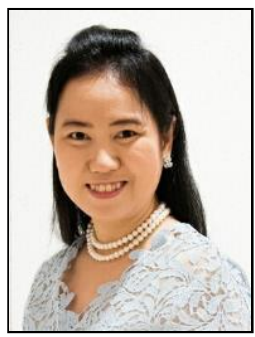

Panita Wannapiroon is an associate professor at the Division of Information and Communication Technology for Education, Faculty of Technical Education, King Mongkut's University of Technology North Bangkok (KMUTNB), Thailand. Presently, she works in the field of ICT in education. She is a member of the professional societies, the Apec Learning Community Builders, Thailand (ALCOB) and the Association for Educational Technology of Thailand (AETT). 